\title{
SYNTHESIS AND CHARACTERIZATION OF A NOVEL FERROSPINEL BIOCOMPOSITE MATERIAL
}

\author{
Gülbahar Akkaya Sayğılı \\ Department of Chemistry, Faculty of Education, Dicle University, 21280 Diyarbakır, Turkey
}

\begin{abstract}
In this study, microwave-assisted activated carbon was produced from lentil processing waste $\mathrm{K}_{2} \mathrm{CO}_{3}$ chemical activation at optimum production conditions. The synthesized optimal activated carbon with a high surface area $\left(1875 \mathrm{~m}^{2} / \mathrm{g}\right)$ was used as a matrix for ferrospinel composite. $\mathrm{CuFe}_{2} \mathrm{O}_{4}$ nanoparticles were embedded to the synthesized optimal activated carbon and a novel magnetic composite material was fabricated. A detailed structural and textural analysis of as-prepared ferrospinel composite material was made by using various characterization techniques including Fourier transform infrared spectroscopy, Brunauer-Emmett-Teller analysis, X-ray photoelectron spectroscopy, and Vibrating sample magnetometer analyses.
\end{abstract}

Key words: Lentil waste, microwave energy, ferrospinel composite, $\mathrm{CuFe}_{2} \mathrm{O}_{4}$ nanoparticles

\section{Introduction}

Renewable resources are abundant worldwide in the form of raw materials, which come from terrestrial/marine animals, agricultural plants, microorganism and their residues. Sustainable biomass materials derived from these raw materials have provided an opening for the development of new alternatives to replace traditional petro-materials for a variety of purposes, including green energy, paint, food packaging, and biomedical applications. Besides, iron oxide based materials (magnetic materials) have been the focus of the nanostructured magnetic materials and have been extensively studied due to their high natural abundance, low cost and due to being environmentally benign. Magnetic materials are a novel category of the adsorbents where a base adsorbent material is embedded with magnetic micro or nano particles that are oxides of metals such as Fe, Co, and Ni [1]. Magnetic materials possess unique properties and hold great potential in biomedical and environmental applications. In this study, a renewable resource namely lentil processing waste was used as an activated carbon precursor and then the synthesized activated carbon was used as a matrix material for synthesis of magnetic material. The produced magnetic material was characterized in terms of physical and chemical properties.

\section{Materials and Method}

\subsection{Biomaterial and chemicals}

Lentil processing waste (LW) was suppled as crude biomaterial by a lentil processing factory at Batman in Turkey. $\mathrm{FeCl}_{3} .6 \mathrm{H}_{2} \mathrm{O}, \mathrm{CuCl}_{2}, \mathrm{~K}_{2} \mathrm{CO}_{3}, \mathrm{NaOH}$, and $\mathrm{HCl}$ were bought from Sigma-Aldrich Company.

\subsection{Synthesis of lentil processing waste activated carbon by microwave-assisted chemical activation with $\mathrm{K}_{2} \mathrm{CO}_{3}$}

*Corresponding author: Address: Department of Chemistry, Faculty of Education, Dicle University, 21280 Diyarbakır, Turkey. E-mail address: bahar.akkaya@dicle.edu.tr, Phone: +904122481000 
In this study, prior to carbonization process conducted in a tubular furnace, the mixture of the LW and $\mathrm{K}_{2} \mathrm{CO}_{3}$ was treated with microwave (MW) energy. MW heating operations were carried out in a household type microwave furnace (Bosch, Model HMT84G451/36, $2450 \mathrm{MHz}$ ). The input power of the MW equipment was set at $900 \mathrm{~W}$ and the MW frequency used was $2.45 \mathrm{GHz}$. Crushed and sieved LW samples were blended with $\mathrm{K}_{2} \mathrm{CO}_{3}$ to the wanted activating chemical/precursor ratio (weight of $\mathrm{K}_{2} \mathrm{CO}_{3} /$ weight of $\mathrm{LW}$ ) in Teflon beakers $\left(100 \mathrm{~mL}\right.$ ). The $\mathrm{K}_{2} \mathrm{CO}_{3}$ impregnated samples were immediately subjected to MW treatment for 30 seconds. After that, the MW treated samples were subjected to carbonization.

\subsection{Lentil processing waste activated carbon optimization procedure}

To fabricate optimal activated carbon, a temperature programmable stainless-steel tubular reactor (7.0 cm diameter x $100 \mathrm{~cm}$ length) in horizontal shape was used. The optimum conditions for activated carbon from LW were assigned by investigating the impacts of impregnation ratio (IR; 1:1, 2:1, 3:1 and 4:1; $\mathrm{K}_{2} \mathrm{CO}_{3} / \mathrm{LW}$, w/w), carbonization temperature (CT; 600, 700, 800, and 900 $\left.{ }^{\circ} \mathrm{C}\right)$ and carbonization time $(\mathrm{Ct}$; 0.5, 1.0, 2.0 and $4.0 \mathrm{~h})$. At each step, 7.0 $\mathrm{g}$ of the dried $\mathrm{LW}$ treated with $\mathrm{K}_{2} \mathrm{CO}_{3}$ in the MW device for $30 \mathrm{sec}$ and then put into the tubular reactor. The $\mathrm{N}_{2}$ flux was at a ratio of $100 \mathrm{~mL} / \mathrm{min}$ and the heat rate for whole patterns was fixed to be $10^{\circ} \mathrm{C} / \mathrm{min}$. The fabricated ACs were washed with hot distilled water till $\mathrm{pH}$ of the filtrate became neutral. The washed ACs were dried at $110^{\circ} \mathrm{C}$ for 24 hours and kept in glass bottles.

\subsection{Preparation of the spinel ferrite composite}

$\mathrm{CuFe}_{2} \mathrm{O}_{4}$ spinel ferrite nanoparticles were loaded to the synthesized optimal activated carbon (LWAC) applying the co-precipitation method by the following procedure: $0.02 \mathrm{~mol} \mathrm{CuCl}_{2}$ and $0.04 \mathrm{~mol} \mathrm{FeCl} 3.6 \mathrm{H}_{2} \mathrm{O}$ were dissolved in $400 \mathrm{~mL}$ distilled water and thereafter $4.8 \mathrm{~g}$ of LWAC was added to the this mixture. With severe magnetic stirring, $5 \mathrm{M} \mathrm{NaOH}$ was added drop by drop to increase the mixture $\mathrm{pH}$ to round 10. This severe stirring was proceeded for 1 hour. Later on, the mixture was heated to $100{ }^{0} \mathrm{C}$ for 2 hours. Then, the prepared magnetic ferrospinel composite was washed with distilled water and separated from water by a simple magnetic procedure. Finally, the synthesized material was dried at $110^{\circ} \mathrm{C}$ in an oven for 24 hours.

\subsection{Characterization studies}

The surface chemical functionalities of samples was qualitatively determined by Attenuated total reflection Fourier transform infrared (ATR-FTIR) spectroscopy with a Perkin Elmer spectrum 100 spectrometer between $4000-650 \mathrm{~cm}^{-1}$.

Porosity analysis was carried out with nitrogen sorption at $77 \mathrm{~K}$ using a TriStar 3000 volumetric adsorption analyzer (Micromeritics, USA). Brunauer-Emmett-Teller (BET) and Barrett-JoynerHalenda (BJH) methods were used to determine the specific surface area and the pore-size distribution (PSD) of the composite material. Prior to analysis, the pattern was degassed under vacuum at $300{ }^{\circ} \mathrm{C}$ for $12 \mathrm{~h}$.

The valence states of $\mathrm{Fe}, \mathrm{Cu}$ and $\mathrm{C}$ on the surface of $\mathrm{CuFe}_{2} \mathrm{O}_{4}$ /activated carbon composite was determined by high resolution X-ray photoelectron spectroscopy (XPS, Thermo ESCALAB 250, USA) using a monochromatic Al K $\alpha$ X-ray radiation source $(1486.7 \mathrm{eV})$. 
Vibrating sample magnetometer (VSM 7404, Lake Shore Cryotronics, USA) was utilized to magnetic features of the synthesized material.

\section{Results and Discussion}

\subsection{Selection of the optimal activated carbon}

To manufacture optimal activated carbon, the impacts of IR, CT and Ct process agents on the $\mathrm{S}_{\mathrm{BET}}$ and VT were investigated. It was found that the optimum fabrication conditions of LWAC were: 3:1 IR, $800{ }^{\circ} \mathrm{C} \mathrm{CT}$ and $1 \mathrm{~h} \mathrm{Ct}$, accompanied with the MW treatment conditions of $900 \mathrm{~W} \mathrm{MW}$ power and $30 \mathrm{sec} \mathrm{MW}$ radiation time. The experimental run and the textural properties of LWAC were given in Table 1. LWAC obtained at optimized setup had a high $\mathrm{S}_{\text {BET }}$ of $1875 \mathrm{~m} 2 / \mathrm{g}$ and a large VT of $0.995 \mathrm{~cm} 3 / \mathrm{g}$. The efficiency of AC fabrication was determined as $38 \%$ and Dp was $1.97 \mathrm{~nm}$ at optimized fabrication setup. The LWAC obtained under optimum conditions was used in the preparation of the spinel ferrite composite.

\subsection{Characterization studies}

\subsubsection{FTIR}

An infrared spectrum of composite system is illustrated in Fig. 1. The absorptions bands located around 2900 and $3300-3500 \mathrm{~cm}^{-1}$ can be assigned to the stretching vibrations of aliphatic $\mathrm{C}-\mathrm{H}$ and $\mathrm{O}-\mathrm{H}$ (hydroxyl or carboxyl), respectively. A broad band at $1060 \mathrm{~cm}^{-1}$ characteristic to the vibration of C-O-C group. Two major peaks at $575.5 \mathrm{~cm}^{-1}$ and at $432.6 \mathrm{~cm}^{-1}$ which come from the stretching vibrations of $\mathrm{Fe}^{3+}-\mathrm{O}^{2-}$ in the tetrahedral complex and $\mathrm{Cu}^{2+}-\mathrm{O}^{2-}$ in the octahedral complex. These results allow us to propose that the formation of $\mathrm{CuFe}_{2} \mathrm{O}_{4} / \mathrm{AC}$ composite has occurred. 


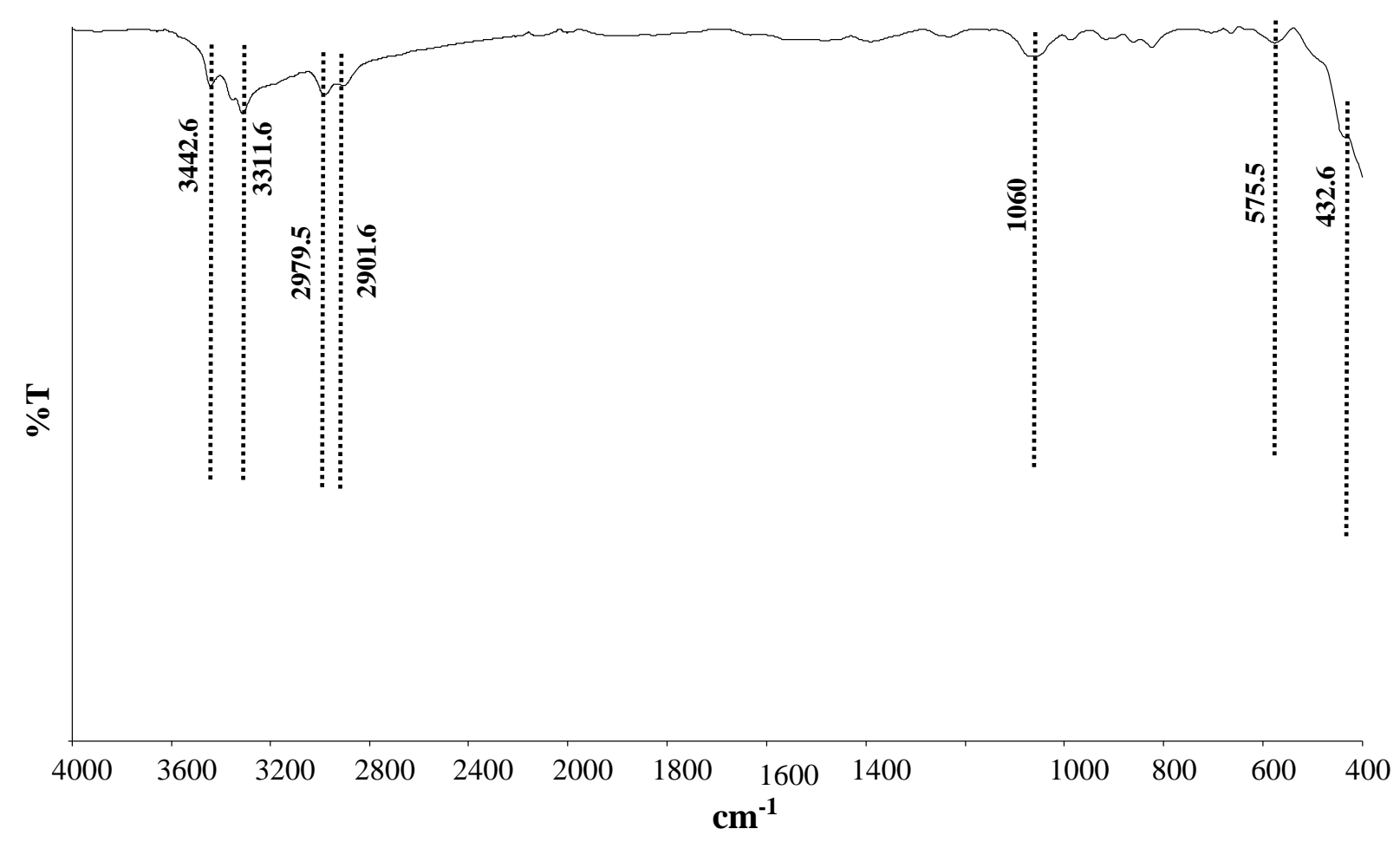

Figure 1. FTIR spectrum of $\mathrm{CuFe}_{2} \mathrm{O}_{4} / \mathrm{AC}$ composite.

\subsubsection{XPS}

The survey and deconvoluted XPS spectra of the $\mathrm{CuFe}_{2} \mathrm{O}_{4} / \mathrm{AC}$ composite was shown in Figure 2be. The survey spectra (Fig. 2b) of magnetic carbon composite depicted the existence of $\mathrm{Cu}, \mathrm{Fe}, \mathrm{C}$ and $\mathrm{O}$ elements. As revealed in the high-resolution spectra of $\mathrm{Cu} 2 \mathrm{p}$, the binding energies at 934.5 and $953.9 \mathrm{eV}$ correspond to $\mathrm{Cu} 2 \mathrm{p} 3 / 2$ and $\mathrm{Cu} 2 \mathrm{p} 1 / 2$, and two very intense satellite peaks of $\mathrm{Cu}^{2+}$ at 942.2 and $962.8 \mathrm{eV}$ are observed [5]. For the Fe 2p spectrum (Fig. 2d), two dominant peaks at $711.5 \mathrm{eV}$ and $724.7 \mathrm{eV}$ with satellites at 717.5 and $732.5 \mathrm{eV}$, which can be assigned to the Fe 2p3/2 and $\mathrm{Fe} 2 \mathrm{p} 1 / 2$ of $\mathrm{Fe}^{2+}$ and $\mathrm{Fe}^{3+}$ states in the composite sample [6]. In Fig. 2e, the $\mathrm{C} 1 \mathrm{~s}$ peak profile can be fitted into four parts: the major peak at $284.5 \mathrm{eV}$ is corresponded to non-oxygenated $\mathrm{C}$ in aromatic ring ( $\mathrm{sp} 2, \mathrm{C}=\mathrm{C} / \mathrm{C}-\mathrm{C}$ ). The weak peaks at $285.6,286.6$ and $288.8 \mathrm{eV}$ are attributed ascribed to $\mathrm{C}-\mathrm{O}, \mathrm{C}-\mathrm{OH} / \mathrm{C}-\mathrm{O}-\mathrm{C}$ and $\mathrm{C}=\mathrm{O}$ bonds, respectively [7]. The results of XPS analysis confirm the successful formation of $\mathrm{CuFe}_{2} \mathrm{O}_{4}$ nanoparticles on the nanoporous carbon surface. 

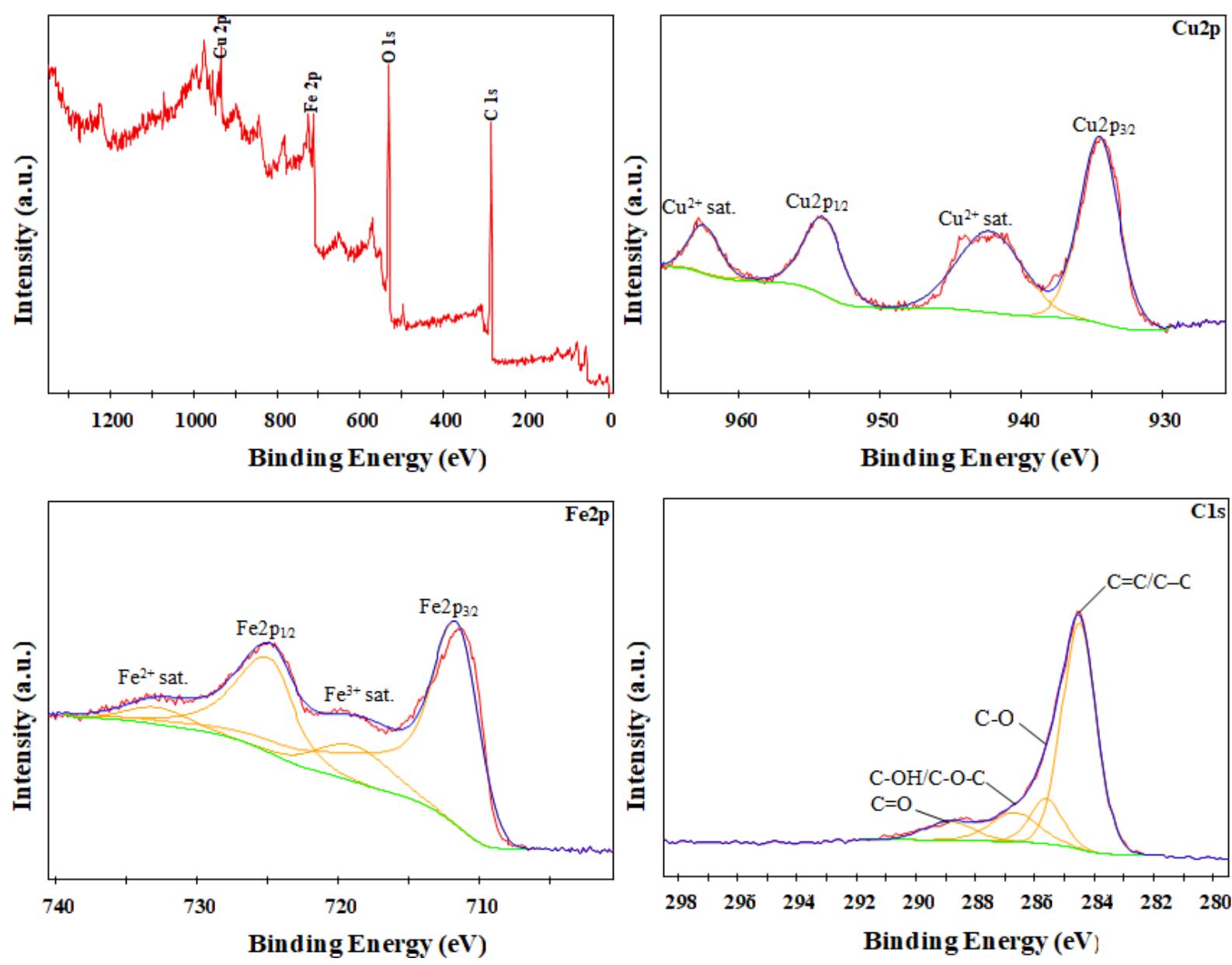

Figure 2. XPS spectra of $\mathrm{CuFe}_{2} \mathrm{O}_{4} / \mathrm{AC}$ composite.

\subsubsection{BET}

The $\mathrm{N}_{2}$ adsorption isotherm and the corresponding PSD (inset) for $\mathrm{CuFe}_{2} \mathrm{O}_{4} / \mathrm{AC}$ is shown in Fig.3. As can be seen from the figure that the isotherm displays a combination of type-I (partly) and typeIV (dominantly) curves in accordance with the International Union of Pure and Applied Chemistry (IUPAC) categorization, indicating the characteristics for micro-mesoporous materials. The $\mathrm{S}_{\mathrm{BET}}$, total pore volume (VT), microporosity (\%Vmic) and mesoporosity (\%Vmes) are $528 \mathrm{~m}^{2} \mathrm{~g}^{-1}, 0.34$ $\mathrm{cm}^{3} \mathrm{~g}^{-1}, \% 58.8$ and $\% 41.2$ respectively. The PSD of composite mainly concentrates on the range of $1-5 \mathrm{~nm}$. The average pore diameter (Dp) is around $2.54 \mathrm{~nm}$ which belongs to micro-mesoporous character. These findings mean that the mesoporous structure of $\mathrm{CuFe}_{2} \mathrm{O}_{4} / \mathrm{AC}$ can contribute to the use in different environmental applications. 


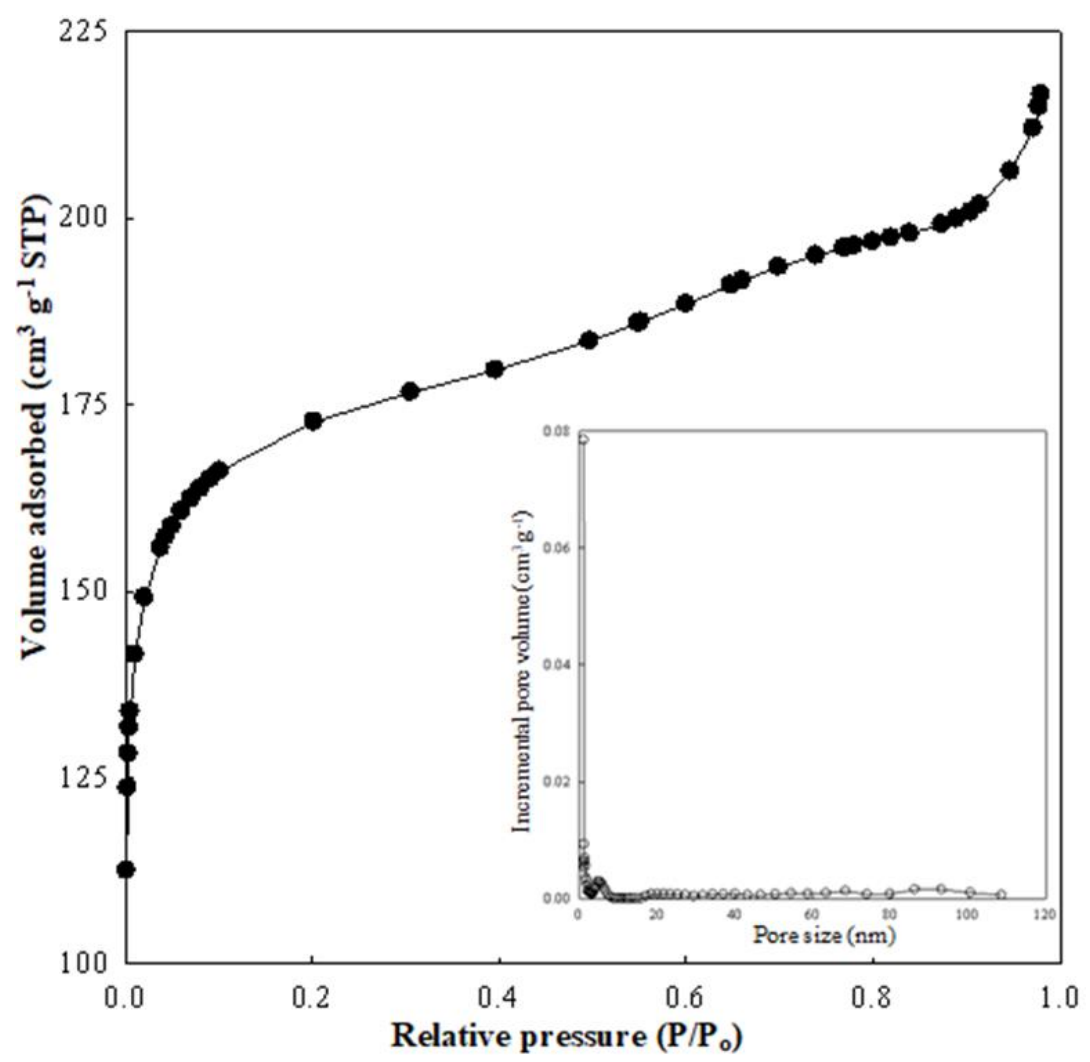

Figure 3. Nitrogen sorption isotherm and pore size distribution curve (inset) of $\mathrm{CuFe}_{2} \mathrm{O}_{4} / \mathrm{AC}$ composite.

\subsubsection{VSM}

The impregnation of $\mathrm{CuFe}_{2} \mathrm{O}_{4}$ nanoparticles to the LWAC was confirmed by the magnetic separation of $\mathrm{CuFe}_{2} \mathrm{O}_{4} / \mathrm{AC}$ by a portable magnet (inset of Fig.4). $\mathrm{CuFe}_{2} \mathrm{O}_{4} / \mathrm{AC}$ was collected on the magnet easily which reflected the advantage of the magnetic separation technique. The magnetic hysteresis loop (Fig.4) in S-shaped curves indicates the superparamagnetic feature of the synthesized spinel ferrite composite. Hence, the composite material prepared as adsorbent in this work can be magnetically separated from the remaining solution and can be used for solid-liquid separations, especially for adsorbing antibiotics, without damaging the adsorbent. 


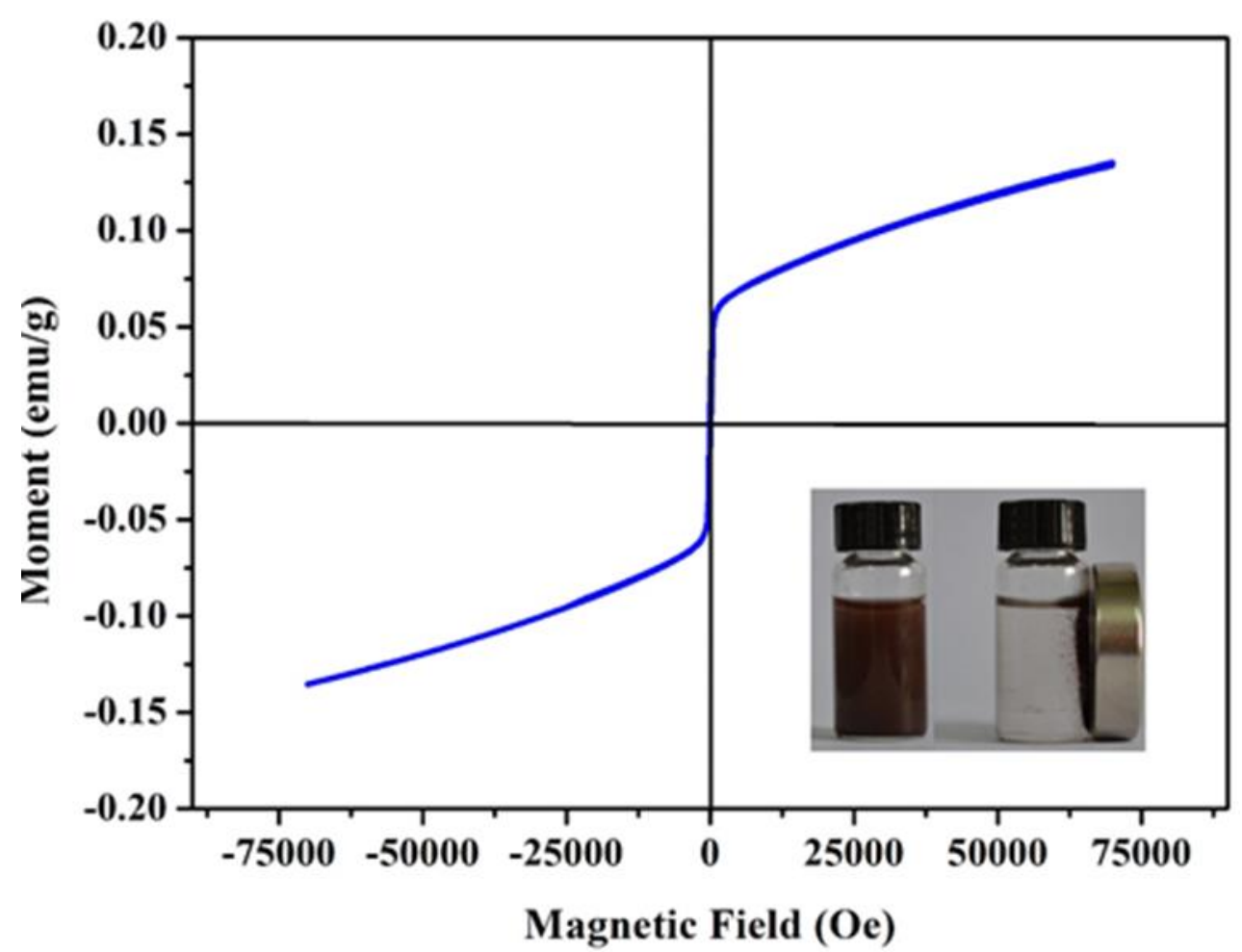

Figure 4. VSM curve of $\mathrm{CuFe}_{2} \mathrm{O}_{4} / \mathrm{AC}$ composite.

\section{Conclusion}

Preferring the usage of lentil waste as the activated carbon precursor to the nonrenewable precursors presents both environmental and economical advantages. $\mathrm{K}_{2} \mathrm{CO}_{3}$ was used as a chemical activating agent under MW heating and an impregnation ratio of 3:1, a carbonization temperature of $800{ }^{\circ} \mathrm{C}$ and a duration time of 1 hour were found the optimal production values regarding high surface area. The produced $\mathrm{CuFe}_{2} \mathrm{O}_{4} / \mathrm{AC}$ was used as a matrix material for $\mathrm{CuFe}_{2} \mathrm{O}_{4}$ nanoparticles loading. Characterization results confirmed the successful production of the composite material.

\section{Acknowledgement}

The author thanks to the Scientific Research Projects Unit of Dicle University (project code: ZGEF.16.014) for the financial support.

\section{References}

[1] Mehta, D., Mazumdar, S., Singh, S.K., "Magnetic adsorbents for the treatment of water/wastewater - A review", Journal of Water Process Engineering, Vol.7,pp.244$265,2015$.

[2] Zhai, S., Li, M., Wang, D., Zhang, L., Yang, Y., Fu, S., "In situ loading metal oxide particles on bio-chars: Reusable materials for efficient removal of methylene blue from wastewater" Journal of Cleaner Production, Vol.220, pp.460-474, 2019. 
[3] Jiao, X., Cai, L., Xia, X., Lei, W., Hao, Q., Mandler, D., "Novel spinel nanocomposites of NixCo1- $\mathrm{xFe}_{2} \mathrm{O}_{4}$ nanoparticles with $\mathrm{N}$-doped graphene for lithium ion batteries" Applied Surface Science, Vol.481,pp.200-208,2019.

[4] Jung, K.-W., Lee, S. Y., Lee, Y. J., "Facile one-pot hydrothermal synthesis of cubic spineltype manganese ferrite/biochar composites for environmental remediation of heavy metals from aqueous solutions", Bioresource Technology, Vol.261, pp.1-9,2018.

[5] Wu, L.-K., Wu, H., Liu, Z.-Z., Cao, H.-Z., Hou, G.-Y., Tang, Y.-P., Zheng, G.-Q., "Highly porous copper ferrite foam: A promising adsorbent for efficient removal of As(III) and As(V) from water", Journal of Hazardous Materials, Vol.347,pp.15-24,2018.

[6] Li, R., Cai, M., Xie, Z., Zhang, Q., Zeng, Y., Liu, G. Liu, H., Lv, W., "Construction of heterostructured $\mathrm{CuFe}_{2} \mathrm{O}_{4} / \mathrm{g}-\mathrm{C}_{3} \mathrm{~N}_{4}$ nanocomposite as an efficient visible light photocatalyst with peroxydisulfate for the organic oxidation", Applied Catalysis B: Environ. Vol.244,pp.974-982, 2019.

[7] Yanga, Z., Huang, Y., Hu, J., Xiong, L., Luo, H., Wan, Y., "Nanocubic $\mathrm{CoFe}_{2} \mathrm{O}_{4} /$ graphene composite for superior lithium-ion battery anodes", Synthetic Metals Vol.242, pp.9298,2018 . 